\title{
O ENSINO DE FILOSOFIA COMO POTENCIALIZAÇÃO A EMANCIPAÇÃO
}

\section{THE TEACHING OF PHILOSOPHY AS A POTENTIALIZATION OF EMANCIPATION}

\author{
Rodolpho Rousseau Soares Silva \\ Recebido em: 05/2018 \\ Aprovado em: 07/2018
}

\begin{abstract}
Resumo: O objetivo pretendido neste estudo é agregar ao ensino de filosofia, sobretudo a prática filosófica este conceito tão importante, a "emancipação". O Ensino Médio é a fase em que os jovens estão por desenvolver a sua maturidade, tanto no âmbito educacional quanto no sociopolítico. Sendo assim, reconhecemos a importância de estimular os estudantes, fornecendo meios para que se desenvolvam para além das habilidades e competências esperadas do ensino de base. O que pretendemos com esta reflexão é lançar bases para novas abordagens de ensino, em específico de filosofia, pois há possibilidades de tornar o ensino de filosofia numa prática filosófica. Para isto, buscamos trazer o ensino de filosofia para a realidade cotidiana dos estudantes, contextualizando o pensamento filosófico e os fatores que os motivaram, tornando-os assim, autônomos para pensarem na realidade no qual estão inseridos de modo crítico e problematizante, tendo como subsídio o referencial teórico aprendido na prática filosófica.
\end{abstract}

Palavras-chave: Emancipação. Ensino de Filosofia. Estímulo.

\begin{abstract}
The aim of this study is to add to the teaching of philosophy, especially the philosophical practice, this important concept, "emancipation". High School is the phase which young people are about to develop their maturity, both in educational and socio-political contexts. Doing this, we recognize the importance of stimulating students by providing means for them to develop beyond the skills and competencies expected from basic education. What we want with this reflection is to lay the foundations for new teaching approaches, specific to philosophy, because there are possibilities of making the teaching of philosophy a philosophical practice. For this, we seek to bring the teaching of philosophy to students' everyday reality, contextualizing philosophical thinking and the factors that motivated them, thus making them autonomous to think about the reality in which they are inserted in a critical and problematizing way, having as to subsidy the theoretical framework learned in philosophical practice.
\end{abstract}

Keywords: Emancipation. Philosophy Teaching. Stimulating.

\section{Introdução}

O conceito de emancipação tem feito parte do escopo da Filosofia há séculos, onde são destinadas diversas finalidades e acepções de sua aplicação, dentre elas a emancipação

\footnotetext{
${ }^{1}$ Universidade Federal de Campina Grande - UFCG. Email: rousseau19@gmail.com 
enquanto ser político, pleno das relações e movimentos de poder que se dão ao seu redor, há também a emancipação intelectual, que exige do indivíduo autonomia ${ }^{2}$ na apreensão de conhecimentos e valores.

No entanto, este conceito tem perdido seu sentido, embora sua importância para a filosofia, sobretudo para educação ainda seja perene. Sem tutela ou interferência de outrem, é o indivíduo que interfere e delibera acerca da sua realidade, ele é o único responsável por suas escolhas, feitas com base em seus conhecimentos, valores e crenças. O que pretendemos desenvolver incide em dispor aos estudantes, através do exercício do filosofar a obtenção de meios para interagir em sociedade, com base em suas compreensões, apropriações e construções de valores e crenças, tornando-os efetivos protagonistas de suas escolhas e atitudes frente ao mundo.

Nossa base teórico-filosófica para o desenvolvimento em sala do conceito de Emancipação, bem como, o estímulo aos alunos buscarem se emanciparem, vem de três importantes filósofos, Immanuel Kant, Theodor Adorno e Jacques Rancière. Embora cada autor traga sua própria teoria sobre a emancipação, vemos nesta diversidade a possibilidade de interagir e contribuir de diversas formas, pois não se trata de eleger uma teoria como a mais eficaz, mas em adotar a que melhor se adeque a cada especificidade.

Dentre os meios metodológicos possíveis para essa prática filosófica, podemos tomar a filosofia como criação de conceitos voltados a solução ou compreensão de problemas. A filosofia deleuzo-guatarriana, concebida como "criação de conceitos" vem reforçar do ponto de vista metodológico o objetivo incutido neste estudo, que tem por finalidade o desenvolvimento do pensamento autônomo em sala. A partir da postura filosófica da criação de conceitos é possível direcionar-se a emancipação, pois ao criar conceitos recortamos o caos, nos afastamos das conformidades, da falsa sensação de estabilidade que o senso comum fornece.

Libertando-se do domínio das opiniões e da tutela intelectual, começamos a pensar por nós mesmo, criando o nosso próprio sistema de crenças, valores e verdades, nos dando a capacidade de reconhecer o outro e perceber os inúmeros pontos de vista e possibilidades, para que de modo racional e refletido possamos exercer nossas escolhas em detrimento ao mundo que nos rodeia.

\footnotetext{
2 Autonomia (in. Autonomy, fr. Autonotnie, ai. Autonomie, it. Autonomia). Termo introduzido por Kant para designar a independência da vontade em relação a qualquer desejo ou objeto de desejo e a sua capacidade de determinar-se em conformidade com uma lei própria, que é a da razão (ABBAGNANO, 2007, p. 97).
} 
A prática filosófica abarcada pela metodologia da criação de conceitos é uma opção de prática que pode ser adotada no ambiente escolar, porém, cabe a cada professor buscar orientar-se por uma postura ou tradição filosófica, pois o importante é fomentar a experiência do filosofar nos estudantes, em prover meios de vivenciar a filosofia, de articular suas características próprias, no exercício continuo de refletir sobre si e sobre o mundo.

\section{As dificuldades de emancipar-se}

A grande problemática acerca de emancipação é que esse termo tem sido empobrecido, em maior grau nos estudos filosóficos acerca do ensino de filosofia. A autonomia tem sido vista como um termo flácido e esvaziado de sentido, ao passo que, há muito se discute e pouco se reconhece as contribuições deste viés. Até nos documentos oficiais que regulam o ensino de filosofia e sua base curricular, a autonomia é citada por diversas vezes. A autonomia prevista na emancipação intelectual tende a reduzir-se a um termo, a uma expectativa a ser cortejada no plano ideal, com pouca pretensão de ser realizado ou estimulado no campo da prática, na sala de aula.

Todavia o que pretendemos, embora exija esforço filosófico e engajamento por parte dos professores e filósofos, não é algo inalcançável ou utópico, pois quando há uma afetação ou estímulo adequado os alunos tendem a desenvolver-se melhor, e isto é percebido em qualquer disciplina, não é um privilégio da filosofia, embora o vasto e profundo embasamento a respeito desta questão, a emancipação, dê a filosofia um dianteira nesta corrida, cujo vencedor é o indivíduo parte desse processo de ensino-aprendizagem.

O modelo de ensino almejado neste estudo visa uma formação educacional com ênfase na formação do indivíduo para o convívio social, mas não somente dispor uma compreensão servil as leis e regras da sociedade, mas a obtenção de visão crítica e aprofundada da real importância das leis. Apenas se reconhecendo como parte da sociedade e tendo um posicionamento crítico das relações que nela se estabelecem, é possível transformar o meio que vivemos, livrando-se de posturas alienantes que segregam minorias, sejam elas religiosas, étnicas, de gênero, além de propagar a violência, a inação política, a corrupção, entre outros.

No que diz respeito à compreensão da importância das leis, não podemos deixar de fazer menção ao filósofo alemão, Immanuel Kant, contemporâneo ao período do iluminismo, apresentou o conceito de esclarecimento, em resposta a Universidade de Berlim, que havia 
realizado a seguinte indagação: "Vivemos em uma época esclarecida?", Kant afirmou que não, mas que vivíamos em uma época de esclarecimento.

Kant levanta os principais fatores que mantém a sociedade na condição de minoridade, ou seja, sob a tutela intelectual de outrem. Segundo o mesmo, dentre os diversos fatores a preguiça, a covardia e o comodismo são os mais recorrentes. Para Kant, também era preciso liberdade para servir-se do próprio entendimento, onde propôs a distinção entre os dois usos da razão, o público destinado a todo e qualquer indivíduo que possa se expressar e questionar as leis, a política e a sociedade em geral. Por último, no que se diz respeito ao uso privado da razão, Kant entende que é necessário privar-se do exercício de se expressar livremente quando estamos no exercício de alguma função social ou estatal.

Em sua visão, Kant defende ser correto, que um indivíduo esclarecido faça uso da razão, em prol do bem geral, bem como, questionar o funcionamento das instituições e da sociedade com o fim de aprimorar, porém quando se está no exercício de uma função pública, como um padre, um magistrado ou um soldado, deve reconhecer que o bem estar geral é mais importante que o individual e por isso é correto obedecer às leis em vigor no caso de um agente público ou aos dogmas da igreja, o padre. No entanto, estando fora do exercício de suas atribuições, todos possuem igual liberdade de expressão.

No que diz respeito aos meios de se emancipar para Kant, ou seja, se tornar esclarecido, parte de um movimento lento e gradual, que depende do indivíduo, ter vontade e coragem para desvencilhar de seu tutor, e assim, poder caminhar com suas próprias pernas, em outras palavras, pensar por si só, buscar sua autonomia intelectual. Este movimento é bem similar ao movimento feito pelo professor, ao prover meios para que os alunos possam se desenvolver por eles mesmos, tendo como base o que foi desenvolvido no processo de ensinoaprendizagem. Em suma, o método Kantiano é um dos mais suscetíveis para ser desenvolvido na prática, basta que haja interesse por parte dos alunos. Nas palavras de Kant: "Sapere aude! Tenha a coragem de te servir de teu próprio entendimento, tal é portanto a divisa do Esclarecimento" (KANT, 1985, p.1).

Theodor Adorno, filósofo e sociólogo alemão, um dos grandes nomes da escola de Frankfurt, influenciado pela filosofia de Immanuel Kant, Karl Marx e outros, desenvolveu seus estudos acerca do conceito da emancipação, tendo como plano de fundo, fatores como: a sociedade, economia, cultura e educação. De acordo com Theodor, fatores socioeconômicos como o capitalismo, a produção em massa tanto nas indústrias quanto na cultura, os resquícios 
do iluminismo com a razão instrumental, foram fatores preponderantes para a eclosão da barbárie.

Sobreviveu ao terror da segunda guerra mundial, viu a educação e a cultura serem utilizados como instrumentos da disseminação de valores, que pregavam o ódio aos judeus, com base nos argumentos defendidos por autoridades políticas e científicas. A falta de pensamento crítico e a aceitação passiva de tais ideais corroboraram para que uma nação irrefletidamente legitimasse a morte de milhares de pessoas em nome de um ideal. Com base no que lhes falavam, erigiram como verdade, em suma os danos irreparáveis acometeram tanto aos judeus nos campos de concentração e extermínio, quanto aos milhões de soldados e civis mortos nos fronts de batalha, em bombardeios e até mesmo condenadas a pena de morte com o fim da grande guerra.

O filósofo Adorno e os estudiosos da escola de Frankfurt investigaram os efeitos da barbárie, não somente a cometida pelos fervorosos nacionalistas alemães, mas as que ainda poderiam acontecer pelo mesmo motivo. A crença inquebrantável nos líderes e nas mídias de massa, sem meios de discernir e valorar o mundo a nossa volta, tendemos a consentir a opinião de outrem como verdade, este é o movimento contrário à emancipação.

Adorno aprofunda estas questões em especial do ambiente educacional observando que esta falta de emancipação favorece o surgimento da barbárie, que está voltada a perda de valores e a adesão acrítica de um comportamento social baseado em pensamentos heterônomos ${ }^{3}$ como os que vieram a culminar no nazismo e no terror vivenciado em Auschwitz, promovido pela falta de valores humanos, junto aos ideais de higiene social, a supervalorização da ciência em detrimento da vida, e até o empobrecimento da cultura e educação foram fatores culminantes desse negativo tal fenômeno social. Adorno amplia a compreensão de barbárie afirmando que:

Entendo por barbárie algo muito simples, ou seja, que, estando na civilização
do mais alto desenvolvimento tecnológico, as pessoas se encontrem
atrasadas de um modo peculiarmente disforme em relação a sua própria
civilização e não apenas por não terem em sua arrasadora maioria
experimentado a formação nos termos correspondentes ao conceito de
civilização, mas também por se encontrarem tomadas por uma agressividade
primitiva, um ódio primitivo ou, na terminologia culta, um impulso de
destruição, que contribui para aumentar ainda mais o perigo de que toda esta
civilização venha a explodir, aliás uma tendência imanente que a caracteriza.

\footnotetext{
${ }^{3}$ Kant contrapõe a Autonomia à heteronomia, em que a vontade é determinada pelos objetos da faculdade de desejar. Os ideais morais de felicidade ou perfeição supõem a heteronomia da vontade porque supõem que ela seja determinada pelo desejo de alcançá-los e não por uma lei sua (ABBAGNANO, 2007, p. 97).
} 
Considero tão urgente impedir isto que eu reordenaria todos os outros objetivos educacionais por esta prioridade (ADORNO, 1995, p. 70).

Com base no objetivo de não tornar a viver tempos tão negativos para o mundo, Adorno levanta uma discussão acerca das instituições de ensino e o que elas têm por dever desenvolver na formação dos educandos, estimulando a criação de novos valores e combatendo pensamentos cristalizados tidos como justificáveis ou naturais, ao passo que, só tendem a reproduzir a barbárie aos indivíduos não emancipados.

Na perspectiva de Adorno, podemos entender a emancipação como o desenvolvimento de ferramentas, que possibilitem analisar o mundo de modo crítico, ou seja, é o desenvolvimento de um indivíduo capaz de refletir a realidade a sua volta. Reconhecer mecanismos de propagação da barbárie, da violência e de fatores negativos ao convívio humano. É a capacidade de fazer uso da história para compreender o presente, e assim construir seus próprios valores, desnaturalizar posturas, tradições e comportamentos heterônomos.

No entanto, este pretenso movimento de emancipar deve vir do próprio indivíduo e não do professor, a emancipação só se dá em sua radicalidade, ou seja, se outros tentam exercer este movimento, já não pode ser chamado de autonomia ou emancipação, visto que cairia numa contradição, por tratar-se de um movimento heterônomo. O filósofo Immanuel Kant, já sinalizava a dificuldade desta imprescindível postura do indivíduo, "É, portanto, difícil para todo homem tomado individualmente livrar-se dessa minoridade que se tornou uma espécie de segunda natureza" (KANT, 1985, p. 2).

Existem diversos fatores impeditivos para a emancipação, cabe a Filosofia o movimento de desnaturalização deste, dentre eles podemos elencar os mais negativos ao processo de emancipação; o modelo de formação dos professores, muitas vezes formulados em moldes que tendem a defender a impossibilidade do filosofar no ensino secundário, sendo assim, o escopo da filosofia no ensino médio seria qualquer outro que não a prática do filosofar.

Ocorre em diversos casos, profissionais que não pretendem atuar como professores ou por algum motivo se veem insatisfeitos e tendem a cumprir minimamente com as exigências que a função de educar demanda. Na obra Escritos Sobre Educação, Friedrich Nietzsche, expõe alguns problemas encontrados na educação alemã, que embora date outro século e outro país, os problemas são atuais e similares a realidade do ensino brasileiro, e se faz necessário apresentá-los, "estes pobres mestres tão numerosos, a que a natureza não concedeu 
dons para uma verdadeira cultura, a que chegaram mesmo à pretensão de fazer às vezes de mestres da cultura, só por que impulsiona a necessidade de ganhar o pão de cada dia" (NIETZSCHE, 1998, p. 113).

O que Nietzsche denuncia não é dificilmente encontrado nos corredores e salas de professores, há de fato, um desânimo em alguns profissionais da educação, e o mais triste de constatar é que de modo geral não são pessoas que não se encontraram no exercício de suas funções, ou apenas insatisfeitas com a remuneração, grande parte está mais insatisfeita com a desvalorização profissional que são acometidos, seja por falta de recursos, estrutura até mesmo o devido valor, que não é dado a educação, que vai desde o alunado, a comunidade escolar, até a esfera governamental.

Tratando diretamente da realidade brasileira do ensino de filosofia, a filósofa Elizete M. Tomazetti, no artigo escrito para a revista Sul-Americana de Filosofia da Educação RESAFE, com o título Sobre ensino, aprendizagem e resistência na aula de Filosofia do Ensino Médio, aponta que não são apenas os alunos que possuem carências em sua formação, os professores não estão sendo preparados na academia para educar nestas especificidades.

É preciso que os professores saiam da posição de culpa e do discurso da falta e tentem atingir os alunos problematizando questões, trazendo a filosofia para a realidade vivenciada por eles. É nisto que incide a noção de resistência, na compreensão de Hannah Arendt, a resistência não se limita a mudança, mas a acontecimentos que instaurem o novo, já na compreensão de Friedrich Nietzsche resistir quer dizer reinsistir, pois não adianta justificar as dificuldades nas limitações estruturais das escolas ou mesmo na formação e cultura dos alunos, o professor deve buscar meios de subverter esta lógica, modificar esta maquinaria, que Foucault já problematizava.

O mundo assim como concebemos já está dado, os problemas são recorrentes, cabe então intervir e buscar modificar o que já está posto, é nisso que consiste a prática filosófica em sala. Tomazetti propõe o ensino de filosofia como resistência, pois segundo a filósofa não adianta reproduzir o discurso de que:

(...) a escola, a sala de aula e o currículo fossem considerados uma caixa blindada, em cujo interior apenas se recitam versos prontos e uma oratória já ensaiada e da qual é impossível fugir, conseguindo-se, no máximo, bater-se, sem sucesso, contra suas paredes de aço (TOMAZETTI, 2010, p. 44).

Conforme descrito anteriormente, a promoção e o incentivo da formação voltada a um caráter emancipatório dos indivíduos é sem dúvida algo difícil, porém necessário, mas que 
depende acima de tudo do mútuo engajamento, sem a adesão espontânea deles, torna-se mais difícil que os estudantes venham desenvolver postura crítica e a partir dela constituam sua emancipação, pois, embora emancipar-se seja algo que só o indivíduo pode fazer por si e para si, é importante que hajam estímulos, acontecimentos, encontros, enfretamentos, e a estes está facultada a presença do professor. Na perspectiva de Rancière é importante afirmar que:

O que pode, essencialmente, um emancipado é ser emancipado: fornecer, não a chave do saber, mas a consciência daquilo que pode uma inteligência, quando ela se considera igual qualquer outra e considera qualquer outra como igual à ela. A emancipação é a consciência dessa igualdade, dessa reciprocidade que, somente ela, permite que a inteligência se atualize pela verificação. O que embrutece o povo não é a falta de instrução, mas a crença na inferioridade da sua inteligência. É o que embrutece os "inferiores" embrutece, ao mesmo tempo, os "superiores". Pois só verifica sua inteligência aquele que fala a um semelhante, capaz de verificar a igualdade das dias inteligências (RANCIERE, 2007, P.64).

Percebemos que assim como em Adorno no conceito de barbárie, a noção de embrutecimento como expõe Rancière é meramente ideológica, fruto de uma construção, ao passo que, é possível através da Filosofia desnaturalizar. O objetivo que almejamos conquistar nos estudantes não se trata de abranger uma totalidade ou mesmo uma minoria, pois, este não é o enfoque principal deste estudo, visamos a potencialização a emancipação.

O professor é como um agricultor que ara o terreno e o deixa pronto para germinar, no entanto, se uma ou mais sementes não brotam não é de todo sua culpa, pois, o seu papel consiste em criar meios para que o solo se torne um ambiente fértil, em outras palavras, espera-se que a sala de aula seja um lugar propício para filosofar. No ponto de vista de Jacques Rancière para que o professor explicador, ou seja, aquele que reconhece o aluno como inferior e define, explica, lhe fornece o concebido como verdade, aja como um embrutecedor, ou seja, um agente contrário à emancipação, deveria ele agir com vista de:

Quem ensina sem emancipar embrutece. E quem emancipa não tem que se preocupar com aquilo que o emancipado deve aprender. Ele aprenderá o que ele quiser, nada, talvez. Ele saberá que pode aprender porque a mesma inteligência está em ação em todas as produções humanas, que um homem sempre pode compreender a palavra de um outro homem (RANCIERE, 2007, p.37).

É importante que haja voluntariedade, ou seja, engajamento do sujeito, pois se o movimento não parte de si próprio ele não se converte em autonomia. Rancière, tende a ser mais radical em sua concepção de autonomia, quando comparado a Adorno ou a Kant, pois, 
para Rancière a autonomia intelectual do indivíduo se constitui quando o reconhece como igual, perante os outros, do ponto de vista intelectual. Só reconhecendo a igualdade das inteligências o indivíduo renuncia à explicação pré-concebida por um mestre explicador, agora ele mesmo se incumbe de buscar suas compreensões do mundo e das coisas.

Rancière concebe o mestre ignorante como um artista, que espera em sua obra o potencial de afetar, de despertar por vias estéticas a compreensão do expectador. Ele foge da explicação, da definição que tanto limita o outro, para ele tornar-se autônomo é reconhecer a igualdade das inteligências e com isto, buscar aprender por si só. Tendo reconhecido a igualdade as inteligências o homem pode tudo, segundo Rancière: "É bem verdade que o homem razoável tudo pode fazer. Mas ele deve aprender a língua própria a cada uma das coisas que quer fazer: sapato, máquina ou poema" (RANCIERE,2007, p.79).

Sabemos que é um desafio significativo fazer uso de uma metodologia que dependa totalmente da autoiniciativa dos alunos, quando em muitas vezes eles não se sentem interessados em sequer cumprir com meras exigências. Porém, percebemos que quando há algo correlacionado aos interesses comuns dos estudantes, este desafio se torna mais próximo do realizável, como o autor aponta, deve haver uma língua própria. Percebemos isto em intervenções do ponto de vista artístico, comportamental, cultural, eles tendem a oferecer uma maior proximidade, por conseguinte maior possibilidade de estimulá-los a produzir.

E aprender por si só vai muito além do profissional e social, consiste em criar meios de compreender a realidade a partir de suas próprias conclusões, sem antes ter passado pelo crivo de outrem e, assim, tornar-se contaminado pela explicação. Além da explicação impor ao aluno a falsa noção de incapacidade frente o mestre explicador e toda sua superioridade, ela também pode conter cargas ideológicas, que quando aceitas acriticamente podem surtir efeitos negativos para a vida, do ponto de vista ético, social, político, entre outros.

Há também aspectos políticos e socioeconômicos excludentes e supressores da busca pela autonomia, podemos novamente fazer um comparativo entre Adorno e Rancière, levando em consideração que os fenômenos sociais são resultados da instrumentalização e uso da educação, cultura, arte e até mesmo da propaganda, é possível reconhecer uma estrutura a que estes ideais disseminados servem, no que tange o ideal de higiene social, o nacionalismo e por fim o nazismo, notamos um viés político-ideológico.

Semelhante ao que ocorre no modelo de educação criticada por Rancière, do mestre explicador, que a todo momento ressalta a necessidade da explicação para o processo de aprendizado. Com base na "diferença", por conseguinte a inferioridade de inteligências em 
detrimento a outras, com isto justificam a divisão social, a ocupação de cargos, posições hierárquicas e no convívio em sociedade, o governo dos eleitos, dos superiores, no entanto, este é mais um discurso naturalizado que tem por objetivo a manutenção do poder de minorias, valendo-se do argumento da desigualdade. Rancière aponta a saída desta autoalienação:

(...) ninguém nasce com mais inteligência do que seu vizinho, que a superioridade que alguém manifesta é somente o fruto de uma aplicação tão encarniçada ao exercício de manejar as palavras quanto a aplicação de outro a manejar instrumentos; que a inferioridade de outrem é a consequência de circunstâncias que não o obrigaram a buscar mais (RANCIERE, 2007, p. $105)$.

\section{Um pretenso norte ao ensino emancipatório}

É com base na importância da emancipação dos indivíduos, que nos debruçamos sobre este estudo. Destinando ao ensino médio e ao ensino de filosofia, o fundamental exercício filosófico de potencializar os estudantes, em vista de garantir-lhes meios para buscarem a emancipação. Valendo-se de uma postura filosófica cujos conhecimentos inerentes da filosofia tendem a serem vivenciados, contextualizados aos problemas e situações no qual os alunos se relacionam, causando assim uma sensibilização, uma afetação, tornando então, a Filosofia um saber usual, experimentável.

E não somente um conhecimento abstrato, historicamente ilustrado. Com fim de conferir-lhes habilidades para outras disciplinas ou exames de ingresso nas universidades ou mercado de trabalho. Os Filósofos Sílvio Gallo e Renata Aspis, justificam a importância do ensino de filosofia no ensino de base, uma contribuição que perpassa do ambiente educacional para a vida prática, segundo os autores:

O que justifica a presença da filosofia como disciplina no currículo do Ensino médio é a oportunidade que ela oferece aos jovens estudantes de desenvolverem um pensamento crítico e autônomo. Em outras palavras permite que eles experimentem "pensar por si mesmos". (...) A filosofia "desnaturaliza" nosso pensamento cotidiano, fazendo com que nós o coloquemos sob suspeita, sob interrogação, nos fazendo "pensar o próprio pensamento (ASPIS \& GALLO, 2009, p.43).

Assim como apregoa Aspis e Gallo, nosso escopo maior é o desenvolvimento da postura crítica, do pensar autônomo, para que então, possa rumar em direção à emancipação. É este exercício de "desnaturalização" que confere aos estudantes a habilidade da suspeita, da 
interrogação e acima de tudo da reflexão, ao passo que, provém da prática docente este estímulo, de impactar, de despertar o olhar crítico, de fazer suspeitar, de agitar sistemas de crenças, valores tidos como absolutos, costumes cristalizados e tidos como "naturais".

Devido hábitos construídos no decorrer de nossas vidas, tendemos a afirmar "isso sempre foi assim" sem sequer questionar o porquê de ser de tal maneira. Segundo Deleuze, "Vemos que o pensamento não é natural, mas forçado; não é somente reconhecido, mas estranho. Nesse contexto de entendimento, "o que é primeiro no pensamento é o arrombamento, a violência, é o inimigo, e nada supõe a Filosofia" (DELEUZE, 1988, p. 230)

Por sua vez o arrombamento a que Deleuze faz menção corresponde ao movimento antes falado de desnaturalização, de desterritorialização das verdades tidas como absolutas, e este movimento é a primeira vista traumático, pois tudo que lhe foi dito, tudo que corriqueiramente aceitamos como verdadeiro e indissolúvel cai por terra, seja mediante argumentação, provocação, ou mesmo com a reflexão.

O movimento de arrombamento nos repele de nosso antigo território, nos desapropria, nos torna órfãos de crenças e convicções há tanto nutridas, no entanto nos apresenta o caos, o mundo como verdadeiramente ele é, nos expõe a condição de criação de apropriação, de reterritorialização, desta vez sobre um solo mais seguro, alicerçado sobre verdades verificadas pelo senso crítico, pelo exercício do pensar e não somente pelo conforto trazido pelas opiniões e verdades pré-dispostas por outros. Correspondente à crítica apresentada por Deleuze e Guattari à falsa impressão de conformidade e regularidade que as opiniões tentam fornecer:

Diríamos que a luta contra o caos implica em afinidade com o inimigo, porque uma outra luta se desenvolve e toma mais importância, contra a opinião que, no entanto, pretendia nos proteger do próprio caos. Num texto violentamente poético, Lawrence descreve o que a poesia faz: os homens não deixam de fabricar um guarda-sol que os abriga, por baixo do qual traçam um firmamento e escrevem suas convenções, suas opiniões; mas o poeta, o artista abre uma fenda no guarda-sol, rasga até o firmamento, para fazer passar um pouco do caos livre e tempestuoso e enquadrar numa luz brusca, uma visão que aparece através da fenda, primavera de Wordsworth ou maçã (DELEUZE \& GUATTARI, 1992, p.261).

Orientados na filosofia deleuzo-guatarriana da criação de conceitos, concebemos a sala de aula e o ensino de filosofia como um acontecimento, como possibilidade de criação, apropriação e construção de conceitos. Na compreensão deleuziana o conceito é: "um conjunto de variações inseparáveis, que se produz ou se constrói sobre um plano de imanência, na medida em que este recorta a variabilidade caótica e lhe dá consistência 
(realidade) (DELEUZE \& GUATTARI, 1992, p.267). A pretensão do ensino da filosofia como criação de conceitos, não se trata de esperar que os alunos criem conceitos complexos, sistemas filosóficos, mas que se apropriem dos conceitos e problemas, que ressignifiquem, deem os seus próprios contornos, assinem o seu conceito.

Para melhor compreender o conceito na perspectiva de Deleuze e Guattari, devemos saber que os conceitos são absolutos e relativos simultaneamente, absolutos em relação a si próprios, absolutos por terem seu próprio problema e ocuparem o seu próprio lugar no plano de imanência, relativos quando relacionados aos demais componentes e conceitos, relativos por que operam uma zona de vizinhança com outros conceitos, podendo até dividir o mesmo plano de imanência.

Todos os conceitos estão interligados e interconectados pelo que os autores chamam de pontes, daí a grande possibilidade de contextualizar, de confrontar os alunos com questões milenares que inquietam a humanidade até os dias atuais. Neste ponto de vista, percebemos que a filosofia pode ser introduzida, não só como componente curricular, mas algo útil a suas vidas, a filosofia não precisa ser um saber restrito aos eruditos e diletantes, através das pontes conceituais podemos interligar a filosofia com a vida dos estudantes. Portanto, para Deleuze e Guattari as pontes conceituais dizem respeito a:

(...) um plano determinável, se passa de um conceito a um outro, por uma espécie de ponte: a criação de um conceito de Outrem, com tais componentes vai levar a criação de um novo conceito de espaço perceptivo, com outros componentes, a determinar (não se chocar, ou não se chocar demais, fará parte de seus componentes) (DELEUZE \& GUATTARI, 1992, p.31).

Por sua vez o plano de imanência é o campo de atuação do conceito, é o solo onde o conceito situa, ele é pré-filosófico, ele não vem antes do conceito, mas é condição necessária para que se produza o conceito, é ele quem demanda o conceito. Portanto unindo ao ensino de filosofia a criação de conceitos como a prática do filosofar, é possível fazer com que os alunos desenvolvam os pré-requisitos necessários para a emancipação, por meio de estímulos provocados como a desnaturalização, que exerce a desterritorialização, ou seja, o abandono das opiniões.

$\mathrm{Na}$ medida em que o estudante se desvencilha de seus preconceitos e antigas representações de verdade absolutas, surge um segundo movimento de apropriação de novas compreensões e valores, pois, o objetivo não é somente reconhecer não saber, como no método socrático, mas tomar o vazio, a ignorância como condição de criação, de aprendizado, 
de reterritorialização, e este movimento é feito de modo autônomo, assim como o mestre ignorante de Rancière, que apenas é um estimulador e não o que dita às verdades explicando.

A apropriação ou roubo como Deleuze defendia, é a condição de propagação do novo, da recriação ou repetição criativa, de subjetivar e dar uma rubrica, de criar conceitos, ou seja, de compreender, problematizar e criar juízos do mundo a sua volta, a partir de si mesmo, autonomamente, de fornecer a sua própria realidade, considerações genuinamente suas e não objeto de outrem. É nisto que consiste o abandono da imposição heterônoma ou tutela, na perspectiva Kantiana ou de Adorno, bem como no desuso da explicação do mestre embrutecedor, segundo Rancière.

\section{Considerações finais}

Com a finalidade de dispor a prática docente uma atitude filosófica, justificada pela busca da potencialização dos estudantes, visando sua emancipação e desenvolvimento para além das exigências profissionais e do convívio social. A perspectiva no qual esta proposta de ensino se presta, visa à interação dos estudantes e indivíduos da sociedade, com o meio que está a sua volta.

Que tenham a capacidade de interagir, intervir e valorar de modo crítico, embasados e munidos de conhecimentos e atitudes, refletindo acerca de suas escolhas, em detrimento da realidade, ao invés de agirem por impulso ou com base em imposições e sugestões de terceiros. Deste modo, os indivíduos que se mantém em constante movimento de busca por emancipar-se, integram os participantes de modo ativo da sociedade, os que buscam melhorias, no âmbito trabalhista, social ou político, ou seja, os que se fazem presentes nos processos e mudanças que o mundo realiza.

Para isso se faz necessário pensar numa educação moldada em perspectivas e abordagens filosóficas, que valorizem o alcance destes fins, sendo assim, justifica unir autores que ergam a bandeira da emancipação, com os que buscam a educação e formação do indivíduo, amparados numa postura própria da filosofia, de visar o mundo, de reconhecê-lo e nele intervir de um modo singular.

Respeitando valores éticos, políticos, epistemológicos, entre outros. Confere ao indivíduo parte desse processo de ensino-aprendizado o objetivo aqui esperado, o de emancipar indivíduos e torná-los por que não emancipadores, promotores de novos ideais e valores, novas práticas e novas políticas. 
Como dito anteriormente cabe ao professor o desafio de fertilizar, de fazer emergir nos indivíduos a vontade neles latente, que as limitações internas e externas que os fizeram entrar em repouso absoluto, com o devido cultivo, ou seja, o devido estímulo é possível causar o arrombamento e com ele o expurgo de todas estas limitações, que o exercício de emancipação está sujeito.

Seja pelas mais diferentes vias de concepções e uso da emancipação, seja do modo processual e gradativo imaginado para o Kant e revisitado por Adorno, que lembra o processo de caminhar com as próprias pernas, ou seja, quando aptos a caminharem por si mesmo os antes tutelados se converteriam em tutores de suas próprias consciências. Ou mesmo do modo de Rancière que, incialmente, lança o indivíduo de toda e qualquer tutela, e faz com que por si mesmo busque suas explicações, assim como a verdade das coisas.

Os itinerários são inúmeros, tanto do ponto de vista conceitual, quanto pelo aparato filosófico, que contribuirá com esta prática. O que de fato importa é a contribuição ao ensino de filosofia, bem como, aos estudantes, que além de se relacionarem com o conhecimento filosófico de modo vivencial, poderão fazer uso dos saberes para além as exigências educacionais e profissionais, ou seja, terão ferramentas para pensarem acerca de suas vidas e do mundo a sua volta.

\section{Referências}

ABBAGNANO, N. Dicionário de Filosofia. Trad. Alfredo Bosi. $5^{\text {a }}$ ed. São Paulo: Martins Fontes, 2007.

ADORNO, T. W. Educação e Emancipação. Trad. Wolfgang Leo Maar.Rio de Janeiro: Paz e Terra, 1995.

ASPIS, R. L; GALLO S. Ensinar Filosofia: um livro para professores. São Paulo: Atta Mídia e Educação, 2009.

DELEUZE, G. Diferença e Repetição. Trad. Luís Orlandi, Roberto Machado. Rio de Janeiro: Graal, 1988.

DELEUZE, G; GUATTARI, F. O que é a filosofia? Trad. Bento Prado Jr e Alberto Alonso

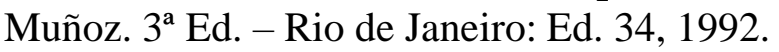

KANT, I. Resposta à pergunta: O que é Esclarecimento? In: KANT, Immanuel. Textos seletos. Trad. Floriano de Souza Fernandes. Petrópolis: Vozes, 1985.

NIETZSCHE, F. Escritos sobre Educação. Trad. Noéli Correia de Melo Sobrinho. Rio de Janeiro: Ed. PUC-Rio; São Paulo: Loyola, 2004.

RANCIERE, J. O mestre ignorante. Trad. Lilian do Vale. $2^{\text {a }}$ Ed. Belo Horizonte: Autentica, 2007.

TOMAZETTI, E. M. Sobre ensino, aprendizagem e resistência na aula de Filosofia do 
Ensino Médio. Revista Sul-Americana de Filosofia da Educação - RESAFE, Brasília, n. 13, p. 41-53, nov./2009 - abr./2010. 